\title{
Commentaries
}

\section{Bridging Psychology and Mathematics Education: Reflections on Boundary Crossing}

\author{
Martha W. Alibali*a, Eric J. Knuth ${ }^{\mathrm{b}}$
}

[a] Department of Psychology, University of Wisconsin-Madison, Madison, WI, USA. [b] Department of Curriculum and Instruction, University of Texas at Austin, Austin, TX, USA.

\begin{abstract}
Collaborations between psychology and mathematics education have the potential to yield progress on critical questions about the teaching and learning of mathematics. In this paper, we describe our experience of collaborating at this boundary. We have found that collaboration has many benefits: it strengthens the research, it is professionally enriching, and it brings novel perspectives to disciplinary communities. However, collaboration is also challenging, because different views about the nature of knowledge and the aims of inquiry can be difficult to bridge. Collaboration can also raise difficult questions about professional identity. We consider several factors that are critical to success in interdisciplinary collaboration, including methodological openness, a broad view of what constitutes "basic" and "applied" research, and an appreciation for diverse perspectives and varying levels of analysis. We close by offering some advice for others who wish to collaborate at the boundary of psychology and mathematics education.
\end{abstract}

Keywords: collaboration, interdisciplinary work, mathematics learning, mathematics education

Journal of Numerical Cognition, 2018, Vol. 4(1), 09-18, doi:10.5964/jnc.v4i1.111

Received: 2016-12-14. Accepted: 2017-06-03. Published (VoR): 2018-06-07.

Handling Editors: Anderson Norton, Department of Mathematics, Virginia Tech, Blacksburg, VA, USA; Julie Nurnberger-Haag, School of Teaching, Learning, and Curriculum Studies, Kent State University, Kent, OH, USA

*Corresponding author at: Department of Psychology, University of Wisconsin-Madison, Madison, WI 53726, USA. E-mail: mwalibali@wisc.edu

This is an open access article distributed under the terms of the Creative Commons Attribution 4.0 International License, CC BY 4.0 (http://creativecommons.org/licenses/by/4.0), which permits unrestricted use, distribution, and reproduction in any medium, provided the original work is properly cited.

Many interdisciplinary collaborations are driven by the desire to solve important scientific or societal problems (National Academy of Sciences, National Academy of Engineering, \& Institute of Medicine, 2005). Collaborations between psychologists and mathematics educators are no exception. As the Call for Papers for this special issue noted, psychologists and mathematics educators are "both deeply invested in research on students' numerical knowledge and development", so the effort to create dialogue across these fields is likely to be fruitful in answering critical questions about the teaching and learning of mathematics.

However, collaborating across disciplinary boundaries can also be challenging. Scholars from psychology and mathematics education may disagree on a range of issues. What are the important questions that should be investigated? What are the best methods with which to approach those questions? What theoretical frameworks should guide those investigations? To what audiences should reports be directed? 
Collaborating across disciplinary boundaries also has many benefits, and scholars from different fields may gain different things from the same collaboration. They may formulate new research questions and learn to use new methodological tools. They may notice patterns in data that might otherwise have remained hidden. They may gain new networks of professional colleagues, new opportunities for training students, new audiences for scholarly work, and new resources for funding research.

We write as collaborators who have worked together at the boundary of psychology and mathematics education for more than 15 years. In this paper, we share some reflections on our experiences. We start by briefly describing the history of our collaboration. We then consider some of the pros and cons of collaborating across mathematics education and psychology. We consider the benefits our collaboration has yielded as well as the challenges we have encountered. In light of these benefits and challenges, we consider what makes our particular collaboration "work". We close by offering some advice for others who might wish to collaborate at this boundary.

\section{Our History}

One of us (Alibali) was trained as a developmental psychologist, with a specialization in cognitive development, and is currently employed in a department of psychology within a college of Letters and Sciences. The other (Knuth) was trained as a mathematics educator and is currently employed in a department of curriculum and instruction within a College of Education. We worked for many years at the same institution (University of Wisconsin - Madison), and we met when we both began work there in 1999.

Our collaboration began with a "seed" of common interest: children's reasoning in early algebra. This content domain is interesting, both from a mathematics education perspective and from a cognitive development perspective. Early algebra represents an important transition period in children's thinking, namely the transition from arithmetic reasoning, which focuses on specific numbers and operations, to algebraic reasoning, which focuses on general quantities and relations. The development of algebraic reasoning involves building from children's informal intuitions about patterns, relationships, and structure to more formalized ways of mathematical thinking. We seek to understand both how children's thinking changes during this period, and how instruction might facilitate and encourage changes in children's thinking.

Our common interests were initially nourished by the opportunity to work together on an interdisciplinary project about early algebra (spearheaded by a mutual colleague, Mitchell Nathan, who was then at the University of Colorado, Boulder). This project was funded by a grant from the Interagency Educational Research Initiative, a joint program of the National Institutes of Health, the National Science Foundation, and the United States Department of Education. Our work on this project compelled us to articulate a set of common research goals, and in this way, it launched our collaboration. It also provided us with an influx of research funds, which enabled us to carry out empirical studies to address our research goals, as well as to support students and research staff.

Over the years, we have written papers together, we have applied for federal grants together, and we have mentored graduate students and postdocs together. We have discovered new things about children's thinking and about instructional practices, and we have experienced the joys of watching trainees learn and grow. We have also experienced our share of challenges, ranging from failed experiments, to uninterpretable data, to 
complicated dynamics within our broader research team. Our collaboration has waxed and waned through the years; at times we have had several active projects together, and at other times few or none. We each maintain an active research program within our own discipline, as traditionally defined. However, for each of us, our approach to research has been influenced by our collaboration. Each of us believes that our collaboration has positively influenced our development as scientists and scholars.

\section{Benefits}

In describing the benefits of interdisciplinary work, Nissani (1997) argued, "Many complex or practical problems can only be understood by pulling together insights and methodologies from a variety of disciplines. Those who forget this simple truth run the intellectual risk of tunnel vision and the social risk of irresponsible action" ( $p$. 209). We believe that this general statement holds true for the specific case of understanding mathematical learning and development. This special issue takes as a point of departure that bridging psychology and mathematics education is a worthwhile endeavor, and the papers in this special issue help build the case for this claim. In this section, we wish to highlight some of the benefits of this endeavor.

One important benefit of interdisciplinary collaboration is that it strengthens the research. Collaborating across disciplinary boundaries provides multiple lenses on important phenomena. It can raise new questions and offer new ways to answer them. It allows for different perspectives to be brought to bear on arguments and claims. It can extend the scope of application for specific conceptual frameworks, and it can push researchers to be clear about their claims and why they matter. It can also provide a wider audience for the research, and it can make findings (as well as each discipline's research base) available to multiple communities.

Although this benefit may hold for interdisciplinary collaborations more generally, it plays out in particular ways at the intersection of psychology and mathematics education. Psychological research on mathematical cognition often fails to use authentic tasks, and as such, its relevance to school-based learning can rightly be called into question. In turn, research in mathematics education often fails to adequately consider general processes of learning and development; as a consequence, intervention studies sometimes yield data that are difficult to interpret. Research that is informed by multiple perspectives can avoid these pitfalls, and the impact of the research is therefore enhanced.

A second benefit of collaboration is that it is professionally enriching. As a direct result of our collaboration, each of us has generated new research questions, met scholars in other fields, learned about funding opportunities, and received invitations to critique others' work and to give professional presentations. As one specific example, several years ago, we worked together on a professional development workshop for middle school mathematics teachers. This experience led us to investigate a new set of questions about teachers' views of students' thinking in early algebra, and it also focused our attention on understanding teachers' choices about modes of communication-an issue that has remained central in our work.

Our collaborative projects have also been professionally enriching for our students and postdocs, who have come from both psychology and education (and from other fields, including mathematics, as well). Indeed, several of our students have gone on to work at the boundary of psychology and education, and some of them describe their experience with interdisciplinary work as "formative" for their career paths. For example, one former graduate student in psychology noted that, before working on our collaborative project, her focus was on 
general processes in learning, memory and cognition, rather than on learning progressions specific to mathematics. Through her work with our research group, her focus shifted to foundational concepts in mathematics and how they build on one another. She noted, "My focus also shifted to considering what is worth knowing. Instead of viewing mathematics problems as a tool for understanding children's cognition, I started to focus specifically on concepts that are important for children to learn" (N. M. McNeil, personal communication, May 1, 2017).

Our mentees have gained research skills, received exposure to new bodies of literature, and learned many practical lessons about how to navigate interdisciplinary work. Through our professional connections, our mentees have also gained access to a rich network of colleagues across disciplines, and these professional relationships contribute to their ongoing scholarly development in a range of ways.

A third benefit of collaboration is that it brings novel perspectives to disciplinary communities. From the perspective of Wenger's communities of practice framework (e.g., Wenger, 1998), "brokers" are individuals who participate in multiple professional communities that share common or related goals (such as the mathematics cognition community and the mathematics education community). Brokers play an important role in translating knowledge and aligning perspectives across communities-and these interactions can provoke and facilitate learning and conceptual change among members of both communities. Thus, collaboration can have consequences, not only for those directly engaged in the collaboration, but for the collaborators' disciplinary communities more broadly. We believe that our mentees' multi-disciplinary training experiences have helped position them to be brokers, as well.

\section{Challenges}

Wenger (2000) noted that "Boundaries are sources of opportunities, but also potential difficulties" (p. 233). Although the benefits of collaboration are many, at the same time, there are also challenges-and in some cases, pitfalls-to crossing boundaries, and specifically to working closely with others who do not share one's assumptions or preconceptions. In this section, we consider some of these challenges and how we have navigated them.

One challenge lies in differing views about research methods, which are undergirded by differing stances about the nature of knowledge. Although a broader discussion of research methods falls outside the scope of this paper (for a thoughtful discussion, see Schoenfeld, 2002), it seems fair to state that research in psychology and in mathematics education tends to rely on different methodological tools, which have different profiles of strengths and weaknesses. Research in psychology tends to rely on experimental methods that incorporate random assignment of participants to conditions, implemented in tightly controlled laboratory settings. These methods (typically) utilize quantitative measures of performance, and they tend to prioritize internal validity over external validity. Mathematics education research, in contrast, utilizes a broad range of both quantitative and qualitative research methods, including design experiments and teaching experiments, as well as clinical interviews and ethnographic and discourse analyses of learning and instructional practices. Much of the research is conducted in authentic settings, such as classrooms or other settings where mathematical reasoning occurs. Broadly speaking, these research designs are intended to highlight and maximize the 
relevance of research to practice, and as such, research in mathematics education tends to prioritize external validity.

Researchers' choices about methods are influenced by many factors-including their epistemological stances, their specific research questions, their individual skill sets, and a range of other practical factors. Although all of these factors are influential, the issue of epistemological stances bears special comment, because different views about the nature of knowledge and the aims of inquiry can be especially challenging to bridge. In our view, collaborators' perspectives need not be perfectly aligned to be able to pursue joint work that is valuable to each—albeit perhaps for different reasons. Collaborators from different fields may sometimes "agree to disagree" on certain aspects of their joint work.

In our specific case, we align with researchers who advocate mixed-methods approaches and a pragmatic, outcome-oriented philosophical stance (e.g., Johnson \& Onwuegbuzie, 2004; Morgan, 2007). From this perspective, one should address research questions using methods that have the best chance of yielding useful answers to those questions. Depending on the research question, this may mean drawing on primarily quantitative, primarily qualitative, or mixed methods. It may mean using inductive logic, deductive logic, or a combination of the two in framing inquiry.

In our program of research, we have worked together on studies that have utilized a wide range of research methods, and we have often combined approaches within a single investigation (e.g., large-scale quantitative assessments of students' knowledge at various time points, paired with in-depth interviews of a subset of students). We-and our audiences_may find different strands of our work on a particular issue more or less convincing or important. For example, some members of our audience may be compelled by quantitative analyses of age trends in students' thinking (e.g., Knuth, Stephens, McNeil, \& Alibali, 2006), whereas others may be compelled by rich descriptions of teachers' views of student thinking (e.g., Asquith, Stephens, Knuth, \& Alibali, 2007). By combining approaches, and by presenting multiple, related forms of data on a single issue or a set of related issues, we broaden the impact of the work.

Our effort to combine the strengths of different research approaches has also led to methodological innovations. One focus of our work has been on the role of teachers' gestures in connecting ideas during classroom mathematics instruction. Psychological studies of gesture in communication typically use wellcontrolled video-based lessons that involve teacher actors producing scripted speech and gestures. However, such lessons lack ecological validity, as they are not authentic instruction or even authentic communication. In our collaborative work, we developed a hybrid method in which we "staged" lessons with real teachers and small groups of students, and we videotaped these lessons. After teaching a lesson twice, teachers received a tutorial about ways to link ideas using gestures, and they then taught the same lesson twice more, to two more small groups of students. We then presented a subset of these video lessons to new groups of students and evaluated their learning about the target concepts. Using this approach, we showed that students learned more from a lesson a teacher gave after the tutorial about linking ideas via gestures than from a lesson he gave before the tutorial (Alibali, Young, et al., 2013). This "staged lesson" approach is a methodological innovation that emerged out of our efforts to maximize both internal and external validity.

A second challenge of interdisciplinary research is the potential for scholars to "fall through the cracks" in terms of disciplinary identity. Most academic gatekeeping mechanisms, such as peer review, grant funding, and 
hiring, are set up to favor traditional disciplinary scholars. Researchers whose work falls in the interstices between fields may have difficulties navigating situations in which professional identity matters.

One arena where this issue plays out is in publishing. Where should scholars who work at the boundary of mathematics education and psychology publish their work: in traditional mathematics education journals, in traditional psychology journals, or in interdisciplinary journals, which may be less widely read and less highly regarded? For beginning researchers, especially, there may be professional costs to publishing in journals that are not top-ranked, that have narrow readership, or that are outside of one's primary disciplinary field.

Even after deciding on a target journal, the review process may be challenging, and there are professional costs to experiencing lengthy and difficult review processes. As succinctly captured in a recent tweet, "My heart says yes but my head says what if the journal won't publish such cutting edge interdisciplinary research"? (Academia Obscura, 2016). In some cases, one may need to "give up" angles or analyses that one cares about, in order to assuage reviewers' and editors' concerns. As one example, we once submitted a manuscript on teachers' gestures in classroom instruction to a mathematics education journal. The paper presented both quantitative analyses of teachers' use of gestures and qualitative descriptions of how teachers use gestures at "trouble spots", when students encounter difficulty in understanding the material. In the review process, the anonymous reviewers requested a much richer and expanded qualitative analysis, and the issue editor specifically asked us to include a wider range of qualitative examples. To deliver on this request while keeping the manuscript of reasonable length, we had to cut back on the quantitative analyses that we presented. We ultimately decided to omit some of the quantitative evidence that we thought would be compelling to (at least some) members of our intended audience. The final version of the manuscript reports only the most important quantitative analysis, and it includes detailed qualitative analyses of two key episodes.

The reviewers also seemed to struggle with the value of our work. One of them asked us to state directly in the paper that "your research is fine-grained foundational research, not immediately connected to the improvement of mathematics education." Of course, we were willing to acknowledge this, but we also sought to emphasize the value of such research for understanding and designing instruction. We believe that the final paper (Alibali, Nathan, et al., 2013) is a strong piece, even though its final form differs greatly from our initial vision for it. It seems clear that the challenges we experienced in publishing this paper derived in part from its not being aligned with the reviewers' disciplinary expectations.

The potential to "fall through the cracks" can be an issue, not only for publishing, but also for professional identity, more broadly. What does it mean to be a developmental psychologist or to be a mathematics educator? For interdisciplinary scholars, it is important to consider and address issues of community membership in the professional arena. When a scholar's work falls at the boundary between fields, to which community does that individual belong? At what conferences and in which societies does that individual feel "at home"? Scholars who cross boundaries may feel like outsiders or may feel at the fringes in many settings. For these reasons, it may be beneficial to cultivate relationships with other "boundary crossers", in order to form a community of individuals facing similar challenges who can support and help one another (Groth, 2015).

In this regard, it bears mention that cultivating relationships with researchers in other fields may have professional costs, if the time and energy spent on those relationships takes away from other efforts. Early career researchers should recognize that scholars from outside ones' primary field may not be viewed as appropriate evaluators for promotion and tenure cases. In our view, the long-term benefits of such professional 
relationships usually outweigh the potential costs. However, the very need to raise the issue indicates that we have a long way to go before our methods of evaluating beginning scholars align with the ethos of boundary crossing and interdisciplinary work.

\section{Factors That Enable Successful Collaboration}

Our collaboration has been fruitful, both in objective terms (e.g., papers published, grants received, students mentored) and in our subjective sense that is has been beneficial, both for us and for our students. Why has it "worked" for us? What are the key ingredients in successful collaboration at the boundary between psychology and mathematics education?

In our view, one critical factor is what we call methodological openness. By this, we mean an openness to and appreciation of the value of a range of different research methods-of their merits and their limitations. Of necessity, then, methodological openness requires some familiarity with, and perhaps even some formal training in or exposure to a variety of research methods. In our collaboration, each of us has been exposed to and has sought to learn about a range of research methods. As students, each of us had experiences that provided us some familiarity with methods that are not commonly used in our primary fields. Alibali's undergraduate major was in the humanities, and it included substantial course work in linguistics and some in anthropology. Her graduate work in cognitive development included substantial exposure to experimental, sociocultural and cross-cultural approaches to understanding cognition and development. Knuth's undergraduate major was in engineering, but his elective course work included a significant focus in psychology. His graduate work in mathematics education included substantial exposure to various learning theories, as well as a graduate certificate in cognitive science. Each of us learned something about the conceptual frameworks and associated research methods used in the other's primary field, even before coming to our collaboration. In our view, these experiences helped make us better and more effective collaborators, and they helped each of us to appreciate the merits (and limitations) of the research methods sometimes advocated by the other.

A second critical factor, in our view, is a broad and inclusive perspective on what constitutes "basic" and "applied" research. The traditional view is that "basic" research is conducted without regard for application-it is a quest for deep understanding and it reveals fundamental truths. In contrast, "applied" research is guided by considerations of use; it is intended to provide solutions to practical problems. In our view, however, these considerations and aims are deeply intertwined. The careful study of how learning and instruction occur in realworld, authentic situations can reveal deep understanding of these processes-and as such, it is a natural part of the quest for deep understanding in an area. Likewise, research directed at basic processes-including research conducted in controlled settings—can uncover information that can be fruitfully applied in practice, or that can form the foundation for effective instructional interventions. We seek to design our investigations to yield information relevant both to "basic" questions, such as those about processes of thinking and learning, and to "applied" questions, such as those about specific instructional approaches and about the design of curricular and professional development materials.

A third critical factor, in our view, is the sense that diverse perspectives and varying levels of analysis are valuable. Even as collaborators, we may prioritize different aspects of a research design or different measures 
of students' or teachers' thinking or behavior. For example, one collaborator may prioritize individual assessments of children's knowledge, while the other may prioritize analyses of social interactions. One collaborator may focus on the endpoint of learning, while the other may focus on the varying paths by which students reach that endpoint. One collaborator may wish to analyze student thinking at a global level, while the other may wish to take a more "micro" approach. Each collaborator can be interested in a specific research question or a specific dataset for different reasons. A respect for and a desire to understand other views are essential for successful collaboration.

Finally, we would be remiss if we did not mention the value of institutional support and research funding in fostering collaboration. We were fortunate to work together at an institution that has a strong commitment to interdisciplinary work, which is manifested both in institutional structures such as research centers (e.g., the Wisconsin Center for Education Research), and in institutional practices such as hosting interdisciplinary research colloquia and providing financial support for interdisciplinary work (e.g., opportunities to apply for "seed money" for research projects). We were also fortunate to receive external research funding to support our empirical studies and to support graduate students and postdocs, enabling us to build a community of scholars that now goes well beyond our current institutions.

At the same time, however, we believe that the most essential ingredients in interdisciplinary collaboration are not resources or institutional support, but instead are the attitudes and practices of individual collaborators. We turn next to these attitudes and practices, and we discuss them in the guise of advice for those who wish to initiate and maintain collaborations at the boundary between psychology and mathematics education

\section{Advice for Those Who Wish to Engage in Interdisciplinary Collaboration}

An obvious first question is how to get started. How does one become engaged in a professional community that is not the community in which one was educated? How does one begin to engage in "boundary interactions", and eventually to find collaborators? One way is simply to "show up"-that is, to attend conferences and professional meetings outside of one's primary disciplinary area, and to talk to other scholars whose work may relate to one's own interests. Another way is to read the work of scholars outside of one's primary discipline and to communicate with them individually. It takes repeated, sustained interactions in order to learn the perspectives, values, and motivations of members of another community. Professional relationships rarely develop without substantial effort; they must be invested in and cultivated.

A second question is what kinds of attitudes and practices foster productive collaboration. Here, we have three pieces of advice. First, cultivate methodological openness, both in yourself and in your students. One way to do this is to make a concentrated effort to learn to use-or at least to learn about-other methodological approaches. In this regard, be mindful of the ways in which training practices in your discipline may serve to dissuade students from methodological openness. In our view, the strong emphasis in psychology methods training on identifying confounds and maximizing internal validity, for example, may actually serve to inhibit interdisciplinary collaboration by elevating one research approach (and implicitly devaluing others). In your research group, cultivate an ethos in which frank discussion of both the strengths and the limitations of different research methods are discussed. 
Second, seek opportunities to learn about related fields, and encourage your students to seek such opportunities, as well. Read the literature, attend colloquia, take or audit courses, and seek out interactions with scholars in other fields. These practices are a form of "continuing education" in the sense that engaging in them helps build one's knowledge base and opens new possibilities for collaborative work. Encouraging these practices in graduate students will help them build a strong foundation for future work at the boundaries between disciplines.

Third, allow time for interdisciplinary work to develop and evolve. It may take time to understand the assumptions and preconceptions that you and your potential collaborator hold, and to understand how they do or do not align. It may take longer to finalize a research design when that design must address multiple goals at the same time. It may take more time to figure out how to assuage a cranky reviewer, when that reviewer's assumptions differ from yours. Give yourself time to navigate boundary interactions thoughtfully and in ways that help build bridges.

\section{Closing Thoughts}

On balance, we believe that mathematics educators and psychologists have much to offer one another, and that through collaboration and interdisciplinary work, we will make greater progress on issues that are important to members of both communities. Challenges arise in every collaboration, but we believe that responding to these challenges can be fruitful in many ways. In our view, there is much to be gained—on both sides-from collaborations that bridge psychology and mathematics education.

\section{Funding}

The authors have no funding to report.

\section{Competing Interests}

The authors have declared that no competing interests exist.

\section{Acknowledgments}

The authors have no support to report.

\section{References}

Academia Obscura. (2016, June 11). My heart says yes but my head says what if the journal won't publish such cutting edge interdisciplinary research [Tweet]. Retrieved from https://twitter.com/academiaobscura/status/741570996885422080

Alibali, M. W., Nathan, M. J., Church, R. B., Wolfgram, M. S., Kim, S., \& Knuth, E. J. (2013). Gesture and speech in mathematics lessons: Forging common ground by resolving trouble spots. ZDM - International Journal on Mathematics Education, 45, 425-440. doi:10.1007/s11858-012-0476-0 
Alibali, M. W., Young, A. G., Crooks, N. M., Yeo, A., Ledesma, I., Nathan, M. J., . . Knuth, E. J. (2013). Students learn more when their teacher has learned to gesture effectively. Gesture, 13(2), 210-233. doi:10.1075/gest.13.2.05ali

Asquith, P. S., Stephens, A. C., Knuth, E. J., \& Alibali, M. W. (2007). Middle-school mathematics teachers' knowledge of students' understanding of core algebraic concepts: Equal sign and variable. Mathematical Thinking and Learning, 9 , 249-272. doi:10.1080/10986060701360910

Groth, R. E. (2015). Working at the boundaries of mathematics education and statistics education communities of practice. Journal for Research in Mathematics Education, 46(1), 4-16. doi:10.5951/jresematheduc.46.1.0004

Johnson, R. B., \& Onwuegbuzie, A. J. (2004). Mixed methods research: A research paradigm whose time has come. Educational Researcher, 33(7), 14-26. doi:10.3102/0013189X033007014

Knuth, E. J., Stephens, A. C., McNeil, N. M., \& Alibali, M. W. (2006). Does understanding the equal sign matter? Evidence from solving equations. Journal for Research in Mathematics Education, 37, 297-312.

Morgan, D. L. (2007). Paradigms lost and pragmatism regained: Methodological implications of combining qualitative and quantitative methods. Journal of Mixed Methods Research, 1(1), 48-76. doi:10.1177/2345678906292462

National Academy of Sciences, National Academy of Engineering, \& Institute of Medicine (2005). Facilitating interdisciplinary research. Washington, DC, USA: The National Academies Press. doi:10.17226/11153

Nissani, M. (1997). Ten cheers for interdisciplinarity: The case for interdisciplinary knowledge and research. The Social Science Journal, 34(2), 201-216. doi:10.1016/S0362-3319(97)90051-3

Schoenfeld, A. (2002). Research methods in (mathematics) education. In L. English (Ed.), Handbook of international research in mathematics education (pp. 435-487). Mahwah, NJ, USA: Erlbaum.

Wenger, E. (1998). Communities of practice: Learning, meaning and identity. Cambridge, United Kingdom: Cambridge University Press. doi:10.1017/CBO9780511803932

Wenger, E. (2000). Communities of practice and social learning systems. Organization, 7(2), 225-246.

doi:10.1177/135050840072002 